\title{
ENDOGONE LACTIFLUA (ZYGOMYCOTA, ENDOGONALES) OCCURS IN POLAND
}

\author{
JANUSZ BŁASZKOWSKI, IwONA ADAMSKA, BEATA CZERNIAWSKA \\ Department of Plant Pathology, University of Agriculture \\ Słowackiego 17, 71-434 Szczecin, Poland \\ e-mail: jblaszkowski@agro.ar.szczecin.pl
}

(Received: June 29, 2003. Accepted: January 29, 2004)

\begin{abstract}
Morphological properties of sporocarps and spores of Endogone lactiflua (Zygomycota, Endogonales), a fungus for the first time found in Poland, are described and illustrated. Endogone lactiflua was wet sieved and decanted from a sample taken from the zone extending from the upper soil layer to rhizosphere of Pinus sylvestris growing in a forest dune in northern Poland. The recovered spores mainly occurred in large and compact sporocarps, although both small aggregates with a few spores and single zygosporangia of this fungus were also isolated. Endogone lactiflua is the fourth species of the genus Endogone found to occur in Poland. The distribution of the fungus in the world is also presented.
\end{abstract}

KEY WORDS: hypogeous fungus, distribution, first record, morphology, taxonomy.

\section{INTRODUCTION}

Wet sieving and decanting of a sample collected from the zone extending from the upper soil layer up to rhizosphere of Pinus sylvestris L. revealed many specimens of Endogone lactiflua Berk. et Broome, a fungus so far not recorded in Poland. The aim of this paper is to describe and illustrate the morphological and biochemical properties of the found E. lactiflua specimens, as well as to compare them with those of other most closely related species of this genus. Additionally, the known distribution of $E$. lactiflua in the world is presented.

\section{MATERIALS AND METHODS}

Leaf litter of the upper $(0-5 \mathrm{~cm})$ soil layer, roots and attached soil from a depth of 5-30 cm were collected near $P$. sylvestris using a small garden shovel. In the laboratory, the material was air dried and subsequently refrigerated at $4^{\circ} \mathrm{C}$ until processing.

To extract spores, the leaf litter and soil mixture were wet sieved and decanted (Gerdemann and Nicolson 1963). Two sieves with openings of diameters of 40 and 250 $\mu \mathrm{m}$ were used.

About 100 isolated spores, occurring both in aggregates and singly in the soil, were used to establish single-species cultures with $P$. sylvestris as the plant host. The spores were stored before inoculation in water at $4^{\circ} \mathrm{C}$ for $24 \mathrm{~h}$. After removing soil debris, they were collected in a pipette and transferred onto a compact layer of roots of 10-14-day old seedlings of $P$. sylvestris placed at the bottom of a hole of ca. $1 \mathrm{~cm}$ wide and $4 \mathrm{~cm}$ deep, formed in a wetted growing medium filling $8-\mathrm{cm}$ plastic pots $\left(250 \mathrm{~cm}^{3}\right)$. The growing medium was an autoclaved mixture consisting of two parts $(\mathrm{v} / \mathrm{v})$ of sand of maritime dunes adjacent to Świnoujście, and one part of the upper soil layer collected near $P$. sylvestris growing in a forest. Subsequently, the spores were covered with another layer of roots coming from 2-3 plants of the host, and the roots and sandwiched spores were buried in the growing medium. The cultures were harvested after 12 months to find new spores and to determine the properties of E. lactiflua mycorrhizae.

At harvest, the content of each pot was transferred to a container with water and the plants with roots carefully washed away from the soil. The water soil suspension was subsequently wet sieved and decanted as described above. Roots were stained with $0.1 \%$ trypan blue (Phillips and Hayman 1970) and examined for the presence of mycorrhizae.

Because all attempts to produce new spores and mycorrhizae of $E$. lactiflua failed, morphological properties of $E$. lactiflua spores and their subcellular structures were determined based on at least 100 field-collected spores mounted in polyvinyl alcohol/lactic acid/glycerol (PVLG; Koske and Tessier 1983) and a mixture of PVLG and Melzer's reagent $(1: 1, \mathrm{v} / \mathrm{v})$. Spores were crushed to varying degrees by applying pressure to the coverslip and then stored at $65^{\circ} \mathrm{C}$ for $24 \mathrm{~h}$ to clear their contents from oil droplets. Spo- 
res prepared in such a way were examined under an Olympus BX50 compound microscope equipped with Nomarski differential interference contrast optics. Microphotographs were taken with a Sony 3CDD colour video camera coupled to the microscope.

The used terminology follows that of Pegler et al. (1993). Spore colour was examined under a dissecting microscope on fresh specimens immersed in water. Colour names are according to Kornerup and Wanscher (1983). Nomenclature of arbuscular mycorrhizal fungi found together with E. lactiflua and plants is that of Walker and Trappe (1993) and Mirek et al. (1995), respectively. The specimens were mounted in PVLG on slides and deposited in the Department of Plant Pathology (DPP), University of Agriculture, Szczecin, Poland.

\section{DESCRIPTION AND DISCUSSION}

\section{Endogone lactiflua Berk. et Broome (Figs 1-8)}

Zygosporangia occur in compact sporocarps (Fig. 1), rarely in loose aggregates (Fig. 7) or singly in the soil (Fig. 2).

Sporocarps ovoid to irregular; 1-2.5 × 3-8 mm (Fig. 1); composed of a peridium surrounding up to hundreds randomly and compactly positioned zygosporangia individually enveloped by a hyphal mantle.

Peridium white, pubescent in young sporocarps, gradually deteriorating with age and, thereby, partly or completely revealing the zygosporangia present (Fig. 1).

Mantle (5.0-)11.7(-20.0) $\mu \mathrm{m}$ thick; consists of interwoven, hyaline hyphae, (2.5-)10.7(-22.5) $\mu \mathrm{m}$ wide (Figs 2-7); mantle hyphae adherent to zygosporangia more compactly interwoven than those positioned in the outer region of the mantle, forming a unit sheath easily separating from zygosporangia (Figs 4-6); hyphae of the outer mantle layer branched and interwoven with those of neighboring zygosporangia (Fig. 7).

Zygosporangia melon yellow (5A6) to dark orange (5A8); globose to subglobose; (90-)127(-170) $\mu \mathrm{m}$ diam; sometimes ovoid or broadly ellipsoidal; 100-110 × 120$160 \mu \mathrm{m}$ (Figs 1, 2, 7); with a circular, 13.5-15.0 $\mu \mathrm{m}$ diam, or slightly ellipsoidal, $8.8-10.0 \times 12.5-16.3 \mu \mathrm{m}$, and raised pore at the junction of the larger of the two gametangia (Fig. 8).

Zygosporangial wall consists of a single, smooth, melon yellow (5A6) to dark orange (5A8) layer, (1.5-)2.1(-2.7) $\mu \mathrm{m}$ thick (Figs 3-6).

Zygospore wall single, smooth, hyaline, (0.7-)2.4(-4.1) $\mu \mathrm{m}$ thick, easily separating from the zygosporangial wall (Figs 3-6).

Gametangia hyaline; subglobose, ellipsoidal, prolate or irregular; 32.5-52.5 $\mu \mathrm{m}$ wide, 55.5-110.0 $\mu \mathrm{m}$ long, of unequal size, placed one near another (Figs 3, 6, 8), rarely absent; gametangial wall smooth, 0.7-1.7 $\mu$ m thick at the zygosporangial base (Figs 3, 8); wall of the larger gametangium continuous with the zygosporangial wall; gametangia usually covered by hyphal mantle of zygosporangia (Figs 6,7).

Zygospore contents of hyaline lipid globules.

In Melzer's reagent, mantle hyphae, zygosporangia, and gametangia stain light orange (6A5) to pale red (8A3), crayfish red (9B8), and pale red (8A3) to pastel red (8A4), respectively (Figs 5, 6); the inner region of the hyphal mantle always stains darker than the outer one.
Collection examined: Poland. Jastrzębia Góra $\left(55^{\circ} 18^{\prime} \mathrm{N}\right.$, 1754'E), under P. sylvestris L., 26 Aug. 2000, Btaszkowski J., 2093-2103, 2424-2426 (DPP).

Distribution and Habitat in Poland: Of the ca. 2200 soilroot samples so far collected from under ca. 110 plant species growing in different regions of Poland, spores of $E$. lactiflua were found only in one sample. This sample was collected under $P$. sylvestris growing in a forest dune ca. $500 \mathrm{~m}$ away from the bank of the Baltic Sea located near Jastrzębia Góra in northern Poland.

The fungi accompanying E. lactiflua in the examined sample were Acaulospora lacunosa Morton, Archaeospora trappei (Ames et Linderman) Morton et Redecker, Glomus caledonium (Nicol. et Gerd.) Trappe et Gerd., G. claroideum Schenck et Smith, and G. constrictum Trappe, arbuscular mycorrhizal fungi of the phylum Glomeromycota, probably associated with roots of Calamagrostis arundinacea (L.) Roth, growing near P. sylvestris. Additionally, present were many spores of Complexipes moniliformis Walker emend. Yang et Korf, a fungus known to form ecto- or ectendomycorrhizae with P. sylvestris (Błaszkowski 1989; Wilcox et al. 1983).

Endogone lactiflua is the fourth species of the genus Endogone found to occur in Poland. The earlier revealed species of this genus were E. aurantiaca (Błaszkowski 1997), E. flammicorona (Błaszkowski 1993), and E. maritima (Błaszkowski, Tadych and Madej 1998).

\section{General distribution}

Endogone lactiflua probably has a worldwide distribution. This fungus has been found to be widely distributed from the sea level to subalpine zones of the northwestern Pacific, U.S.A. (Gerdemann and Trappe 1974). Berch and Fortin (1984) revealed E. lactiflua under Sphagnum growing in Quebec, Canada. Endogone lactiflua had many times been encountered in the United Kingdom (Godfrey 1957; Hawker 1954; Pegler et al. 1993; Walker 1985), where it has been considered to be the most commonly occurring species of this genus (Pegler et al. 1993). Additionally, this fungus has been recorded in Portugal (Trappe and Gerdemann 1972), Denmark (Lange 1956; Lange and Lund 1954), Hungary (Szemere 1965), Austria, Germany, and the former U.S.S.R. (Bucholtz 1911; Ławrynowicz 1979).

Mycorrhizal association: Endogone lactiflua occurred in the field among ectomycorrhizal roots of $P$. sylvestris and those with vesicular-arbuscular colonization coming from an adjacent grass. This fungus failed to form new zygosporangia and mycorrhizae in pot cultures with $P$. sylvestris.

Walker (1985) found sporocarps of E. lactiflua associated with ectomycorrhizae of Pinus contorta Dougl. ex Loud. cultivated in boxes filled with sphagnum peat in a greenhouse of Scotland.

The distinctive properties of E. lactiflua are its sporocarps with many spores (Fig. 1), individually surrounded with a hyphal mantle (Fig. 2), the coloured zygosporangial wall being thinner than the colourless zygospore wall (Figs 3-6), as well as the reactivity of the mantle hyphae, the zygosporangial wall and gametangia in Melzer's reagent (Figs 5, 6).

Most of the found sporocarps contain hundreds of spores (Fig. 1), although aggregates consisting of two spores (Fig. 7) and single spores (Fig. 2) were also isolated. The me- 

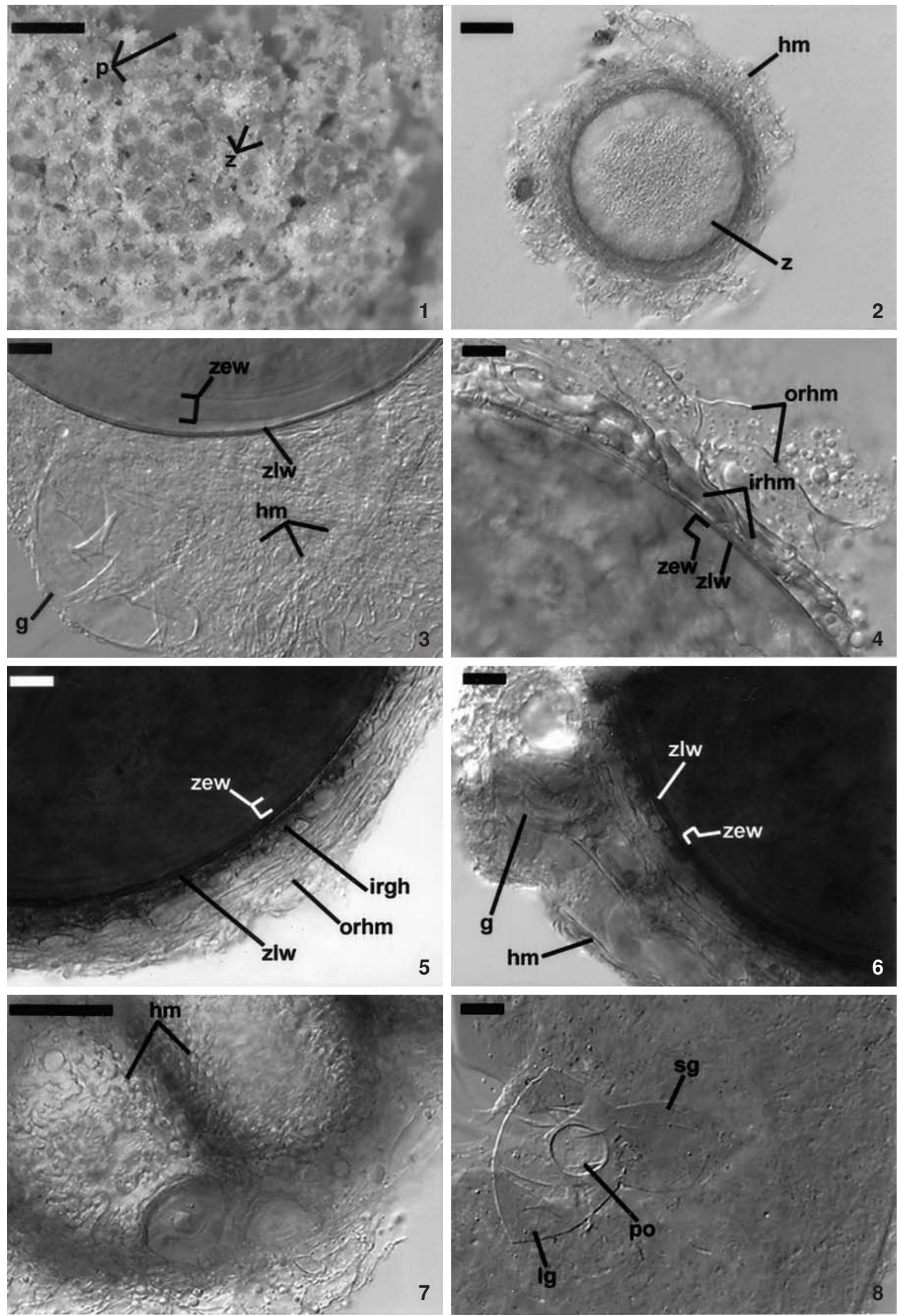

Figs 1-6. Endogone lactiflua. Fig. 1 - Sporocarp with many zygosporangia (z) partly covered with white, pubescent peridium (p). Fig. 2 - Zygosporangium (z) enveloped by hyphal mantle (hm). Fig. 3 - Zygosporangial wall (zlw), zygospore wall (zew), hyphal mantle (hm), and gametangium (g). Fig. 4 and 5 - Outer region (orhm) and inner agglutinated region (irhm) of hyphal mantle adherent to the outer surface of zygosporangial wall (zlw) enclosing zygospore wall (zew). Fig. 6 - Zygosporangial wall (zlw), zygospore wall (zew), hyphal mantle (hm), and gametangium (g). Fig. 7 - Cerebral hyphal mantle $(\mathrm{hm})$ of two zygosporangia seen in a plan view and gametangia $(\mathrm{g})$. Fig. 8 - Larger gametangium (lg) united with smaller gametangium (sg) and slightly raised pore (po) of zygosporangial wall.

Fig. 1 - dried sporocarp; Figs 2-4, 7 and 8 - spores in PVLG; Figs 5 and 6 - spores in PVLG + Melzer's reagent. Fig. 1 - bright field microscopy; Figs 2-8 - differential interference contrast. Bars: Fig. $1=0.5 \mathrm{~mm}$, Figs 2 and $7=50 \mu \mathrm{m}$, Figs 3-6, and $8=10 \mu \mathrm{m}$. 
thod commonly used in collecting of fungi of the genus Endogone is raking and searching through the leaf litter and the upper layer of soil (Gerdemann and Trappe 1974; Pegler et al. 1993). In contrast, the specimens of E. lactiflua presented in this paper were recovered following wet sieving and decanting of a sample taken near the trunk of $P$. sylvestris from the zone extending from the upper soil layer to a depth of $30 \mathrm{~cm}$.

The used sieve with meshes of a diameter of $250 \mu \mathrm{m}$ collected large sporocarps and larger aggregates of E. lactiflua, and that with openings of a diameter of $40 \mu \mathrm{m}$ retained small aggregates and single spores of this fungus. Wet sieving and decanting revealed earlier the formation of single spores also by E. aurantiaca Błaszk., E. flammicorona Trappe et Gerd., E. maritima Błaszk. et al., and an undescribed Endogone sp. (Błaszkowski 1993, 1997; Błaszkowski et al. 1998). Błaszkowski et al. (1998) suggested that the formation of sporocarps culminates the ontogenetical development of this group of fungi, and the size of sporocarps may depend on stability, as well as physical and chemical properties of the soil, in which a given fungus occurs.

The hyphal mantle surrounding each spore consists of interwoven hyaline, branched and sometimes inflated hyphae forming a dense net (Figs 2-7). In the outer region, the tangles of the mantle hyphae are looser and their branched or swollen fragments frequently rise over the surface of the mantle (Figs 2-5). The inner region of the mantle forms highly interwoven and agglutinated hyphae grew from an almost unit, innermost zone of the mantle adherent to the outer surface of the zygosporangial wall (Figs 4-6).

In cross-sectional view, the hyphal mantle consists of many tightly adherent layers (Figs 2-6). When seen in a plane view, the mantle resembles a cerebrum (Fig. 7).

The mantle hyphae stain readily and intensively red in Melzer's reagent (Figs 5, 6); however, the staining reaction is always darker in the inner region of the mantle than in the outer one. This property has not been mentioned in any earlier descriptions of the fungal species. The red reaction of the mantle hyphae in Melzer's reagent also occurs in $E$. alba (Petch) Gerd. et Trappe (Yao, Pegler and Young 1992), E. pseudopisiformis Y.J. Yao (Yao et al. 1995b), E. maritima Błaszk. et al. (Błaszkowski et al. 1998), and Youngiomyces carolinensis Y.J. Yao (Yao et al. 1995a).

The coloured wall of zygosporangia is smooth (Figs 3-6, 8) and composed of many tightly adherent sublayers (laminae). As the sublayers are very thin and inseparable even in vigorously crushed spores, they are exceptionally difficult to see. Examination of the zygosporangial wall, at high magnifications of a compound microscope equipped with Nomarski interference contrast optics, readily reveals its complex structure. The important property of the E. lactiflua zygosporangial wall is its immediate and intensively red staining after mounting spores of this fungus in Melzer's reagent (Figs 5, 6).

The colourless zygospore wall is semiflexible (Figs 3-6). It tightly adheres to the inner surface of the zygosporangial wall and is markedly thicker than the wall of a zygosporangium in most of the specimens examined. In crushed spores, this wall usually separates from the wall of a zygosporangium. In a few spores, the thickness of the zygospore wall is similar and even lower than that of the zygosporangial wall. These specimens probably represent early deve- lopmental stages of this fungus. In members of the phylum Glomeromycota, producing similar spores, the ontogenetical development of their spores begins the formation of outer layers or walls, and the inner layers/walls start to develop when the differentiation of the phenotypic and biochemical properties of the preceding layers/walls are fully completed (Stürmer and Morton 1997). Thus, in immature spores, the present subcellular structures may represent both their transitional and terminal developmental stages and, hence, they may be mistakenly interpreted.

Although gametangia are usually present in most of the E. lactiflua specimens examined in this study, they frequently are difficult to see because of their cover by the hyphal mantle (Figs 6,7). One of the two co-occurring gametangia always is larger, usually has a thicker wall, and is associated with a pore of the zygosporangium (Figs 3, 6, 8 ). The second gametangium has no contact with the zygosporangium. This agrees with the Trappe and Gerdemann's (1972) finding that zygosporangia of E. lactiflua develop from the tip of the larger gametangium, as do those of E. flammicorona and E. maritima (Błaszkowski et al. 1998).

The fungal species of the genus Endogone, producing spores most similar morphologically to those of E. lactiflua, are E. flammicorona and E. maritima. All the species form yellow-coloured and individually mantled spores with a zygosporangial wall thinner than that of a zygospore. The main differences separating the three fungi reside in the ability to form sporocarps, morphological and biochemical properties of their hyphal mantle and spores, as well as in features of their gametangia.

Spores of E. lactiflua and E. flammicorona occur mainly in large and compact sporocarps surrounded by a peridium (Gerdemann and Trappe 1974; this study). The sporocarps usually comprise many (even hundreds) spores (Fig. 1). In contrast, most spores of E. maritima are grouped in small, 2-3-spored sporocarps lacking a peridium and were also frequently found singly in the soil (Błaszkowski et al. 1998).

While the hyphal mantle of spores of E. lactiflua consists of many layers of tightly interwoven hyphae appearing netted in a cross-sectional view (Figs 2-6), that covering $E$. flammicorona spores is composed of a single layer of spirally arranged hyphae resembling flame-shaped projections in a cross section (Gerdemann and Trappe 1974). Both the hyphal mantle and spores of E. lactiflua stain intensively red in Melzer's reagent (Figs 5, 6). In contrast, the zygosporangial wall of E. flammicorona becomes only yellow to pale orange in this reagent (Gerdemann and Trappe 1974).

The gametangia of E. lactiflua are present in most specimens of this fungus and are thick-walled at maturity (Fig. 3 ), and those of E. flammicorona are ephemeral, thin-walled, and generally are invisible on mature spores (Gerdemann and Trappe 1974). Additionally, the gametangia of the former fungus are markedly wider [up to $52.5 \mu \mathrm{m}$, this study; up to 65(-80) $\mu \mathrm{m}$, Gerdemann and Trappe 1974] than those of the latter species [up to 35(-40) $\mu \mathrm{m}$, Gerdemann and Trappe 1974].

Apart from the differences listed above, the distinguishing property of E. maritima zygosporangia is their nonreactivity in Melzer's reagent (Błaszkowski et al. 1998; vs. intensively red staining in E. lactiflua when mounted in this reagent, Figs 5, 6). 
Other related fungi producing zygosporangia surrounded with a hyphal mantle are E. aurantiaca, Youngiomyces multiplex (Thaxt.) Y.J. Yao, and Y. stratosus (Trappe, Gerd. et Fogel) Y.J. Yao.

The conical warts ornamenting the surface of the zygosporangial wall of E. aurantiaca (Błaszkowski 1997) contrast most with the smooth-walled outer surface of $E$. lactiflua zygosporangia (Figs 3-6, 8).

The basis for the erection of the genus Youngiomyces and the new combinations $Y$. multiplex and $Y$. stratosus from E. multiplex Thaxt. and E. stratosa Trappe, Gerd. et Fogel has been the formation of zygosporangia from gametangia separated from each other (Yao et al. 1995a). In $E$. lactiflua and all other members of the genus Endogone, zygosporangia bud from the tip of the larger gametangium always associated with the second, smaller one (Figs 7,8).

\section{ACKNOWLEDGMENT}

This study was supported in part by the State Committee for Scientific Research (KBN), grant no. 6.P04G.100.19.

\section{LITERATURE CITED}

BERCH S.M., FORTIN J.A. 1984. Some sporocarpic Endogonaceae from eastern Canada. Can. J. Bot. 62: 170-180.

BŁASZKOWSKI J. 1989. The occurrence and geographic distribution of E-strain ectendomycorrhizal fungi in Poland. Bull. Pol. Ac. Biol. 37: 19-31.

BŁASZKOWSKI J. 1993. The occurrence of arbuscular fungi and mycorrhizae (Glomales) in plant communities of maritime dunes and shores of Poland. Bull. Pol. Ac. Sci. Biol. 41: 377-392 .

BŁASZKOWSKI J. 1997. Endogone aurantiaca, a new species in the Endogonales from Poland. Mycotaxon 63: 131-141.

BŁASZKOWSKI J., TADYCH M., MADEJ T. 1998. Endogone maritima, a new species in the Endogonales from Poland. Mycol. Res. 102: 1096-1100.

BUCHOLTZ F. 1911. Die Gattung Endogone Link. I. In: Neue Beiträge zur Morphologie und Cytologie der unterirdischen Pilze. Ryga, 108 pp., 8 tab.

GERDEMANN J.W., NICOLSON T.H. 1963. Spores of mycorrhizal Endogone species extracted from soil by wet sieving and decanting. Trans. Br. Mycol. Soc. 46: 235-244.

GERDEMANN J.W., TRAPPE J.M. 1974. The Endogonaceae in the Pacific Northwest. Mycologia Mem. 5: 1-76.
GODFREY R.M. 1957. Studies of British species of Endogone. I. Morphology and taxonomy. Trans. Br. Mycol. Soc. 40: 117-135 .

HAWKER L.E. 1954. British hyphogeous fungi. Phil. Trans. Br. 237: 429-546.

KOSKE R.E., TESSIER B. 1983. A convenient, permanent slide mounting medium. Newsl. Mycol. Soc. Am. 34: 59.

KORNERUP A., WANSCHER J.H. 1983. Methuen handbook of colour. 3rd Ed. E. Methuen and Co., Ltd., London. 252 pp.

LANGE M. 1956. Danish hyphogeous macromycetes. Dansk Bot. Arkiv 16, 7-80.

LANGE M., LUND E.M. 1954. The genus Endogone in Denmark. Fresia 5: 90-95.

ŁAWRYNOWICZ M. 1979. Endogonales, kłębiankowate. In: A. Skirgiełło, M. Zadara, M. Ławrynowicz. Grzyby X. Warszawa-Kraków, pp. 273-295.

MIREK Z., PIĘKOŚ-MIRKOWA H., ZAJĄC A., ZAJĄC M. 1995. Vascular plants of Poland. A Checklist. Polish Botanical Studies, Guidebook 15, Kraków, 303 pp.

PEGLER D.N., SPOONER B.M., YOUNG T.W.K. 1993. British truffles. A revision of British hypogeous fungi. Royal Botanic Gardens, Kew. 216 pp. +26 plates.

PHILLIPS J.M., HAYMAN D.S. 1970. Improved procedures for clearing roots and staining parasitic and vesicular-arbuscular mycorrhizal fungi for rapid assessment of infection. Trans. Br. Mycol. Soc. 55: 158-161.

STÜRMER S.L., MORTON J.B. 1997. Developmental patterns defining morphological characters in spores of four species in Glomus. Mycologia 89: 72-81.

SZEMERE L. 1965. Die unterirdischen Pilze des Karpatenbeckens. Akadémiai Kiadó. Budapest. 5-319 + 10 plates.

TRAPPE J.M., GERDEMANN J.W. 1972. Endogone flammicorona sp. nov., a distinctive segregate from Endogone lactiflua. Trans. Br. Mycol. Soc. 59: 403-407.

WALKER C. 1985. Endogone lactiflua forming ectomycorrhizas with Pinus contorta. Trans. Br. Mycol. Soc. 84: 353-355.

WALKER C., TRAPPE J.M. 1993. Names and epithets in the Glomales and Endogonales. Mycol. Res. 97: 339-344.

WILCOX H.E., YANG C.S., LOBUGLIO K. 1983. Responses of pine to E-strain ectendomycorrhizal fungi. Plant and Soil 71: 239-247.

YAO Y.-J., PEGLER D.N., YOUNG T.W.K. 1992. Revision of the type of Endogone alba (Endogonaceae). Mycotaxon 45: 109-122.

YAO Y.-J., D.N. PEGLER D.N., YOUNG T.W.K. 1995a. Youngiomyces, a new genus in Endogonales (Zygomycotina). Kew Bull. 50: 349-357.

YAO Y.-J., PEGLER D.N., YOUNG T.W.K. 1995b. New species in Endogone (Endogonales). Kew Bull. 50: 359-365. 